\title{
Komitmen Organisasi pada Pemain Wayang Orang yang Berstatus Aparatur Sipil Negara
}

\author{
Seilla Arummaysha Salsabilla1, Aditya Nanda Priyatama', Selly Astriana ${ }^{3}$ \\ 1,2Universitas Sebelas Maret; Jalan Ir Sutami 36 A Surakarta, (0271) 645252 \\ e-mail: *1salsabillaseilla@gmail.com, 2adityanandapriyatama@gmail.com, \\ ${ }^{3}$ sellyastriana13@gmail.com
}

\begin{abstract}
Wayang orang is an Indonesian Culture identity that requires strategy to continue to be present in community. The Culture Office of Surakarta appoints wayang orang player as State Civil Apparatus (ASN) to conserve wayang orang's existence.This study aims to determine relationship between job security and self perceived employability with organizational commitment on wayang orang players in Sriwedari Surakarta with 71 respondents as sample. Research data collected by organizational commitment scale $(\alpha)$ 0,850 , job security scale $(\alpha) 0,927$, and self perceived employability scale $(\alpha) 0,887$. Results showed significant relationship between job security and self perceived employability with organizational commitment $\left(\mathrm{F}_{\text {Change }}=41,772>\mathrm{F}_{\text {Table }}=3,13 ; \mathrm{p}=0,000<0.05\right)$. Job security and self perceived employability contributes $55,1 \%$ to organizational commitment. Partial test showed significant relationship between job security and organizational commitment $(p=0,000<0.05)$ and insignificant relationship between self perceived employability and organizational commitment $(\mathrm{p}=0,813>0,05)$.
\end{abstract}

Keywords: Organizational Commitment, Job Security, Self Perceived Employability

Abstrak. Wayang orang merupakan identitas Budaya Indonesia yang memerlukan strategi agar dapat terus hadir di masyarakat. Salah satu upaya yang dilakukan Dinas Kebudayaan Surakarta adalah mengangkat pemain wayang orang menjadi Aparatur Sipil Negara (ASN). Penelitian ini bertujuan mengetahui hubungan antara job security dan self perceived employability dengan komitmen organisasi pada pemain wayang orang di Sriwedari Surakarta dengan sampel berjumlah 71 responden. Data dikumpulkan menggunakan skala komitmen organisasi $(\alpha)$ 0,850, skala job security $(\alpha)$ 0,927, dan skala self perceived employability $(\alpha) 0,887$. Hasil penelitian menunjukkan hubungan yang signifikan antara job security dan self perceived employability dengan komitmen organisasi $\left(F_{\text {change }}=41,772>\right.$ $\left.\mathrm{F}_{\text {Tabel }}=3,13 ; \mathrm{p}=0,000<0,05\right)$. Job security dan self perceived employability bersama-sama memberikan sumbangan sebesar $55,1 \%$ terhadap komitmen organisasi. Uji parsial penelitian menunjukkan hubungan yang signifikan antara job security dan komitmen organisasi $(\mathrm{p}=0,000<0,05)$ dan tidak terdapat hubungan yang signifikan antara self perceived employability dengan komitmen organisasi $(\mathrm{p}=0,813>0,05)$.

Kata Kunci: Komitmen Organisasi, Job Security, Self Perceived Employability 


\section{Pendahuluan}

Indonesia merupakan negara kepulauan yang terdiri dari 17.504 pulau serta dihuni oleh sekitar 1.331 suku bangsa (Tomascik, Mah, Nontji, Moosa, 1996; Prasetya, 2017; Badan Pusat Statistik, 2016). Untuk menyatukan wilayah yang luas dan rumit seperti Indonesia, diperlukan beberapa aspek, salah satunya adalah budaya (Ricklefs, 2010). Kebudayaan sendiri memiliki beragam bentuk, salah satunya adalah kesenian (Koentjaraningrat, 2010). Pada kebudayaan klasik Indonesia, jenis kesenian yang sangat menonjol adalah kesenian dalam bentuk visual dan pertunjukan salah satunya wayang (Ricklefs, 2010).

Secara umum, wayang menggambarkan alam pikiran Orang Jawa yang saling bertentangan atau dualistik dengan konsep-konsep baik dan buruk, halus dan kasar, lahir dan batin dalam diri manusia dan menciptakan keseimbangan. (Sumaryoto, 1990). Perkembangan wujud wayang menghasilkan jenis wayang yang beragam, salah satunya adalah wayang orang. Wayang orang adalah kesenian tradisional Jawa berupa pertunjukan teater yang menggabungkan konsep seni drama dengan pertunjukan Wayang (Soedarsono, 1990).

Wayang Orang Sriwedari terbentuk antara tahun 1910-1912 di bawah Keraton Kasunanan Surakarta. Wayang Orang Sriwedari kemudian diambil alih oleh pemerintah pada tahun 1946 (Hersapandi, 1999). Saat ini wayang orang cenderung kurang diminati oleh masyarakat jika dibandingkan dengan pertunjukan atau hiburan lain sehingga keberadaan wayang orang seperti antara ada dan tidak ada (Hadi, 2014). Berdasarkan observasi langsung yang dilakukan selama 1 bulan di Gedung Wayang Orang Sriwedari, jumlah penonton selain Hari Jumat hanya terisi rata-rata tiga baris depan bangku penonton dan jumlahnya tidak lebih dari 50 orang.

Wayang orang sebagai identitas budaya Indonesia memerlukan strategi agar dapat terus hadir di masyarakat (Azhari, 2015). Terdapat tiga kondisi tertentu yang menjadikan suatu hal memiliki eksistensi di masyarakat yaitu kondisi budaya, sosial, dan material (Brown dalam Ahimsa, 2007). Pada wayang orang, kondisi material hadir dalam bentuk gedung, pakaian, alat rias, serta pelaku seni wayang orang itu sendiri (Azhari, 2015). Berdasarkan kondisi tertentu tersebut, pelaku seni wayang orang memiliki peran yang penting (Hadi, 2014). Pemerintah melalui Dinas Kebudayaan mengangkat pemain wayang orang menjadi Aparatur Sipil Negara yang selanjutnya akan disingkat menjadi ASN agar pemain wayang orang memiliki ikatan dengan Dinas Kebudayaan sebagai organisasi yang menaungi (Hersapadi, 1999). 
Philanthrophy Journal of Psychology

Vol 1 Nomor 2 (2017), 129-142

ISSN 2580-6076 (Print), ISSN 2580-8532 (Online)

Berdasarkan observasi dan wawancara langsung di lapangan, terdapat 74 pemain wayang orang yang terdiri dari 24 ASN dengan status PNS dan 50 ASN dengan status tenaga kontrak atau honorer. Pemain perlu mengikuti tata tertib yang berlaku yang diberikan oleh dinas salah satunya yaitu hadir tepat waktu dan memenuhi absen. Berdasarkan observasi yang dilakukan selama 2 minggu, terdapat pemain wayang orang yang absen pada saat pementasan maupun latihan tanpa disertai alasan. Lebih lanjut, meskipun telah diangkat sebagai ASN di Sriwedari, masih terdapat pemain wayang orang yang mengundurkan diri.

Keterikatan pemain wayang orang dengan Dinas Kebudayaan merupakan bentuk komitmen pemain terhadap dinas. Komitmen adalah kekuatan yang dapat mengikat individu untuk melakukan suatu hal dengan tujuan tertentu (Cohen, 1992). Komitmen organisasi sendiri adalah keterikatan yang dimiliki individu dengan organisasi yang dikarakteristikkan melalui keinginan untuk tetap bertahan, identifikasi nilai dan tujuan organisasi, serta kesediaan untuk berusaha lebih dalam berperilaku (Mowday, 1982, Porter dalam Kusumaputri, 2015). Komitmen organisasi dirumuskan dalam tiga komponen yaitu komitmen afektif, continuance, dan normatif. Komitmen afektif melibatkan kondisi emosional individu pada organisasi, komitmen continuance melibatkan persepsi individu terhadap pertimbangan untuk terus berada dalam organisasi, sementara komitmen normatif melibatkan dimensi moral yang didasarkan pada tanggung jawab yang dimiliki individu pada organisasi (Meyer \& Allen, 1991).

Beberapa perilaku positif yang muncul dengan adanya komitmen organisasi diantaranya adalah kesediaan untuk bekerja keras sesuai dengan tujuan organisasi, menerima nilai-nilai organisasi, serta mendukung keberhasilan dan kemajuan organisasi (Luthans, 2005). Oleh karena itu, komitmen organisasi merupakan hal yang perlu dimiliki oleh pemain wayang orang untuk mempertahankan eksistensi wayang orang karena dapat mendukung fungsi dan tujuan dalam mempertahankan budaya yang ada (Kementrian Pariwisata, 2015).

Komitmen organisasi memiliki berbagai faktor yang terdiri faktor pekerjaan, kesempatan yang dimiliki pegawai untuk berkembang dalam organisasi, karakteristik pribadi, hubungan positif antar pegawai, struktur organisasi, serta gaya manajemen (Kusumaputri, 2015). Job security merupakan bagian dari job related factor yang berkaitan dengan tingkat keluar masuk anggota dalam organisasi. Job security didefinisikan sebagai keadaan aman dan stabil dalam bekerja yang diberikan organisasi kepada pegawai (Meltz, 1989; Herzberg, 1968). Penelitian yang dilakukan oleh Wong, Ngo, dan Wong (2002) dan 
Philanthrophy Journal of Psychology

Vol 1 Nomor 2 (2017), 129-142

ISSN 2580-6076 (Print), ISSN 2580-8532 (Online)

Yousef (1998) menunjukkan adanya korelasi positif yang signifikan antara komitmen afektif dengan job security.

Untuk menghadapi perubahan zaman, pemain wayang orang perlu meningkatkan kualitas tidak hanya pada segi teknik namun juga pemahaman etos kerja, karya, serta pengabdian sebagai seorang seniman (Hadi, 2014). Individu lebih memiliki komitmen terhadap organisasi apabila terdapat kecocokan antara apa yang ditawarkan dalam suatu pekerjaan dengan apa yang dicari oleh pekerja atau pegawai (Dawis, 1992). Hillage dan Pollard (dalam Rothwell\&Arnold, 2007) mendefinisikan employability sebagai kapasitas seseorang untuk menempatkan diri dengan tepat dalam pekerjaan yang ditawarkan. Selfperceived employability merupakan asesmen yang dilakukan individu untuk mengetahui kapasitasnya dalam melakukan pekerjaan yang berorientasi pada masa yang akan datang (Rothwell \& Arnold, 2007). Penelitian yang dilakukan oleh De Cuyper dan De Witte (2011) menunjukkan bahwa terdapat korelasi positif yang signifikan antara perceived employability dengan komitmen organisasi.

Upaya untuk mempertahankan eksistensi wayang orang dari sisi organisasi merupakan suatu hal yang patut diteliti sehingga dapat memberikan kontribusi yang bermanfaat bagi keberadaan wayang orang sebagai salah satu budaya di Indonesia khususnya di Jawa. Upaya pemerintah untuk mewadahi mengangkat pemain wayang orang sebagai Aparatur Sipil Negara (ASN) dapat diteliti lebih lanjut untuk mengetahui job security serta self perceived employability pemain wayang orang yang sekiranya memiliki kontribusi terhadap komitmen pemain wayang orang untuk terus tampil di tengah kondisi pementasan wayang orang yang relatif sepi. Berdasarkan latar belakang pemikiran tersebut peneliti tergerak untuk melakukan penelitian hubungan job security dan self perceived employability dengan komitmen organisasi pada pemain wayang orang yang Berstatus Aparatur Sipil Negara di Sriwedari.

\section{Metode}

Penelitian ini merupakan penelitian kuantitatif korelasional dengan satu variabel terikat dan dua variabel bebas yaitu komitmen organisasi sebagai variabel terikat dan job security serta self perceived employability sebagai variabel bebas. Komitmen organisasi adalah kekuatan relatif pemain wayang orang dalam mengidentifikasi diri dan menjadi bagian dari Dinas Kebudayaan, job security adalah keadaan aman dan stabil pemain wayang orang dalam melakukan pekerjaannya tanpa khawatir adanya ancaman pekerjaan, gaji, senioritas, dan hak pensiun, sementara self-perceived employability adalah evaluasi 
subjektif yang dilakukan pemain wayang orang untuk mengetahui kapasitasnya dalam melakukan pekerjaan agar pekerjaan yang dilakukan dapat sesuai dengan kemampuannya dan terlaksana dengan baik.

Data dalam penelitian diambil dari populasi pemain wayang orang yang berstatus ASN di Sriwedari sejumlah 74 orang sehingga penelitian ini merupakan studi populasi. Sampel yang digunakan dalam penelitian ini adalah seluruh pemain wayang orang di Sriwedari yang berstatus ASN dan bersedia menjadi subjek penelitian yaitu sejumlah 71 orang terdiri dari 24 ASN tetap dan 47 ASN tenaga kontrak.

Instrumen yang digunakan untuk mengumpulkan data pada penelitian ini adalah kuesioner yang terdiri dari modifikasi skala Likert pada OCQ (Organizational Commitment Questionaire) berjumlah 24 aitem, skala job security berjumlah 40 aitem, dan Self Perceived Individual Employability Scale berjumlah 16 aitem. Skala memiliki bentuk pernyataan tertutup sehingga subjek hanya memilih satu dari beberapa alternatif jawaban yang sesuai dengan keadaan dirinya dengan memberi tanda (v). Pilihan jawaban yang digunakan terdiri dari aitem pernyataan favorable dan unfavourable.

Tabel 1.

Penilaian Pernyataan Favorable dan Pernyataan Unvaforable

\begin{tabular}{lcc}
\multirow{2}{*}{ Kategori Jawaban } & \multicolumn{2}{c}{ Nilai } \\
\cline { 2 - 3 } & Favorable & Unfavorable \\
\hline SS (Sangat Sesuai) & 4 & 1 \\
\hline S (Sesuai) & 3 & 2 \\
\hline TS (Tidak Sesuai) & 2 & 3 \\
\hline STS (Sangat Tidak Sesuai) & 1 & 4 \\
\hline
\end{tabular}

Uji validitas instrument skala pada penelitian ini didasarkan pada validitas isi dan validitas internal. Pengujian validitas isi dilakukan dengan telaah professional (professional judgment) yang dilakukan oleh dosen Program Studi Psikologi Universitas Sebelas Maret. Uji validitas internal dilakukan dengan menggunakan teknik korelasi Product Moment. Aitem dalam skala merupakan aitem yang valid jika pada pengujian dengan uji dua sisi memenuhi syarat signifikansi 0,01 yaitu nilai $r$ hitung diatas $r$ tabel. Reliabilitas skala dalam penelitian ini diuji dengan formula Alpha Cronbach dengan skala dinyatakan reliabel apabila Alpha Cronbach menunjukkan nilai di atas 0,60.

Metode analisis data yang digunakan untuk menguji hipotesis pada penelitian ini adalah analisis korelasi ganda dan analisis korelasi parsial. Analisis korelasi ganda digunakan untuk membuktikan adanya hubungan antara dua variabel bebas atau lebih secara bersama-sama dengan satu variabel terikat sementara analisis korelasi parsial digunakan untuk mengetahui hubungan antara dua variabel dan mengontrol variabel lain 
Philanthrophy Journal of Psychology

Vol 1 Nomor 2 (2017), 129-142

ISSN 2580-6076 (Print), ISSN 2580-8532 (Online)

yang dianggap memiliki pengaruh. Terdapat uji asumsi sebagai syarat dalam teknik analisis data yaitu uji normalitas yang mengacu pada nilai Kolmogorov-Smirnov > 0,05 dan uji linearitas yang mengacu pada signifikansi $<0,05$. Seluruh perhitungan Perhitungan dilakukan dengan bantuan program Statistical Product and Service Solution (SPSS) versi 22.0 for Windows.

\section{H a s i l}

Tahapan pertama dalam analisis hasil penelitian adalah melakukan uji validitas dan reliabilitas. Pada skala komitmen organisasi didapat 20 aitem valid dengan koefisien reliabilitas alpha sebesar 0,850. Pada skala job security, uji validitas dan reliabilitas menghasilkan 33 aitem valid koefisien reliabilitas alpha sebesar 0,927, sementara pada skala self perceived employability didapat 12 aitem valid dengan koefisien reliabilitas alpha sebesar 0,887. Berdasarkan uji validitas dan reliabilitas, data yang didapat dari ketiga instrument memenuhi persyaratan kehandalan alat ukur.

Tahap selanjutnya yaitu melakukan uji asumsi normalitas dan linearitas. Uji normalitas yang mengacu pada nilai Kolmogorov-Smirnov menghasilkan nilai Asymp. Sig (2tailed) pada skala komitmen organisasi sebesar 0,525 ( $\mathrm{p}>0,05)$, pada skala job security sebesar 0,596 ( $p>0,05)$, dan pada skala self perceived employability sebesar 0,079 $(p>0,05)$ sehingga data penelitian tergolong berdistribusi normal. Sementara untuk uji linearitas variabel job security dengan komitmen organisasi dan variabel self perceived employability dengan komitmen organisasi diperoleh nilai linearity sebesar 0,000 $(\mathrm{p}<0,05)$ sehingga terdapat hubungan yang linear antara variabel-variabel tersebut.

Setelah uji asumsi terpenuhi, uji hipotesis penelitian dilakukan menggunakan korelasi ganda. Analisis korelasi ganda digunakan untuk mengetahui adanya hubungan antara tiga variabel atau lebih yang terdiri dari satu variabel dependen atau variabel terikat dan dua atau lebih variabel independen atau variabel bebas. Hasil dari korelasi ganda yang dilakukan disajikan dalam tabel 1 berikut.

Tabel 2.

Uji Korelasi Ganda

\begin{tabular}{lll}
\hline & \multicolumn{1}{c}{ Nilai } & \multicolumn{1}{c}{ Syarat } \\
\hline Sig. & 0,000 & $\mathrm{p}<0,05$ \\
\hline$F_{\text {hitung }}$ & 41,772 & $F_{\text {hitung }}>F_{\text {tabel }}(3,13)$ \\
\hline$R$ & 0,742 & $\begin{array}{l}\text { interval koefisien korelasi } \\
0,600-0,799=\text { kuat }\end{array}$ \\
\hline $\mathrm{R}^{2}$ & 0,551 & \\
\hline
\end{tabular}


Hasil pada tabel 1 menunjukkan nilai koefisien korelasi ganda (R) 0,742 dengan nilai koefisien determinasi $\left(R^{2}\right)$ sebesar 0,551 atau $55,1 \%$. Uji analisis yang dilakukan selanjutnya adalah uji korelasi parsial pada penelitian yang disajikan pada tabel 2 dan tabel 3 berikut.

Tabel 3.

Uji Korelasi Parsial Job Security dengan Komitmen Organisasi

\begin{tabular}{|c|c|c|c|c|}
\hline \multicolumn{3}{|c|}{ Control Variables } & $\begin{array}{l}\text { Komitmen } \\
\text { Organisasi }\end{array}$ & Job Security \\
\hline \multirow{6}{*}{$\begin{array}{l}\text { Self Perceived } \\
\text { Employability }\end{array}$} & Komitmen & Correlation & 1.000 & .613 \\
\hline & Organisasi & $\begin{array}{l}\text { Significance } \\
\text { (2-tailed) }\end{array}$ & - & .000 \\
\hline & & df & 0 & 68 \\
\hline & Job Security & Correlation & .613 & 1.000 \\
\hline & & $\begin{array}{l}\text { Significance } \\
\text { (2-tailed) }\end{array}$ & .000 & 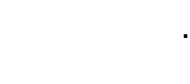 \\
\hline & & $\mathrm{df}$ & 68 & 0 \\
\hline
\end{tabular}

Tabel 4.

Uji Korelasi Parsial Self Perceived Employability dengan Komitmen Organisasi

\begin{tabular}{lllrr}
\hline \multicolumn{2}{l}{ Control Variables } & & $\begin{array}{r}\text { Komitmen } \\
\text { Organisasi }\end{array}$ & $\begin{array}{r}\text { Self Perceived } \\
\text { Employability }\end{array}$ \\
\hline Job Security & Komitmen & Correlation & 1.000 & .029 \\
& Organisasi & $\begin{array}{l}\text { Significance } \\
\text { (2-tailed) }\end{array}$ &. & .813 \\
& & Df & 0 & 68 \\
\cline { 2 - 5 } & $\begin{array}{l}\text { Self } \\
\text { Perceived }\end{array}$ & Significance & .029 & 1.000 \\
Employ- & (2-tailed) & .813 &. \\
ability & Df & 68 & 0 \\
\hline
\end{tabular}

Uji korelasi parsial menghasilkan nilai signifikansi 0,000 pada korelasi parsial antara variabel job security dan komitmen organisasi serta nilai signifikani 0,813 pada korelasi parsial antara variabel self perceived employability dengan komitmen organisasi. Sumbangan efektif yang diberikan variabel job security terhadap komitmen organisasi adalah sebesar 53,6\% dan sumbangan relatifnya sebesar 97\%. Sementara sumbangan efektif yang diberikan variabel self perceived employability terhadap komitmen organisasi adalah sebesar 1,4\% dan sumbangan relatifnya sebesar 3\%.

Selanjutnya, gambaran umum data hasil penelitian dijelaskan dalam kategorisasi berdasarkan analisis deskriptif data empirik yang disajikan pada tabel 4 berikut. 
Tabel 5.

Kriteria dan Kategorisasi Responden Penelitian

\begin{tabular}{llccc}
\hline \multirow{2}{*}{ Variabel } & \multicolumn{2}{c}{ Kategorisasi } & \multicolumn{2}{c}{ Komposisi } \\
\cline { 2 - 5 } & Kategori & Skor & 14 & $19,72 \%$ \\
\hline Komitmen & Tinggi & $65,42 \leq \mathrm{X}$ & 45 & $63,3 \%$ \\
Organisasi & Sedang & $65,42 \leq \mathrm{X}<50,86$ & 12 & $16,9 \%$ \\
& Rendah & $\mathrm{X}<50,86$ & 12 & $16,9 \%$ \\
& Tinggi & $110,7 \leq \mathrm{X}$ & 48 & $67,6 \%$ \\
& Sedang & $110,7 \leq \mathrm{X}<87,7$ & 11 & $15,49 \%$ \\
\hline Self-Perceived & Rendah & $\mathrm{X}<87,7$ & 12 & $16,9 \%$ \\
Employability & Tinggi & $41,46 \leq \mathrm{X}$ & 47 & $66,2 \%$ \\
& Sedang & $41,46 \leq \mathrm{X}<31,18$ & 12 & $16,9 \%$ \\
& Rendah & $\mathrm{X}<31,18$ & &
\end{tabular}

Gambaran umum responden penelitian dapat digolongkan berdasarkan status kepegawaian dan jenis kelamin. Kategorisasi responden penelitian pada skala komitmen organisasi berdasarkan status kepegawaian disajikan pada tabel 5 dan kategorisasi responden penelitian pada skala komitmen organisasi berdasarkan jenis kelamin disajikan pada tabel 6.

Tabel 6.

Kategorisasi Responden Penelitian pada Skala Komitmen Organisasi Berdasarkan Status Kepegawaian

\begin{tabular}{llcc}
\hline \multirow{2}{*}{ Variabel } & \multicolumn{3}{c}{ Komposisi } \\
\cline { 2 - 4 } & \multicolumn{1}{c}{ Kategori } & Jumlah & Persentase \\
\hline ASN PNS (N=24) & Tinggi & 8 & $33,4 \%$ \\
\cline { 2 - 4 } & Sedang & 16 & $66,7 \%$ \\
\cline { 2 - 4 } & Rendah & - & $0 \%$ \\
\hline $\begin{array}{l}\text { ASN Tenaga Kontrak } \\
\text { (N=47) }\end{array}$ & Tinggi & 6 & $12,8 \%$ \\
\cline { 2 - 4 } & Sedang & 29 & $61,7 \%$ \\
\cline { 2 - 4 } & Rendah & 12 & $25,5 \%$ \\
\hline
\end{tabular}

Tabel 7.

Kategorisasi Responden Penelitian pada Skala Komitmen Organisasi Berdasarkan Janis Kelamin

\begin{tabular}{llcc}
\hline \multirow{2}{*}{ Variabel } & \multicolumn{3}{c}{ Komposisi } \\
\cline { 2 - 4 } & \multicolumn{1}{c}{ Kategori } & Jumlah & Persentase \\
\hline Pria $(\mathrm{N}=52)$ & Tinggi & 11 & $21,2 \%$ \\
\cline { 2 - 4 } & Sedang & 31 & $59,6 \%$ \\
\cline { 2 - 4 } & Rendah & 10 & $19,2 \%$ \\
\hline Wanita & Tinggi & 3 & $15,8 \%$ \\
$(\mathrm{~N}=17)$ & Sedang & 12 & $63,2 \%$ \\
\cline { 2 - 4 } & Rendah & 2 & $10,5 \%$ \\
\hline
\end{tabular}

Uji t-test independen pada hasil kategorisasi yang disajikan dalam tabel 5 dan 6 menunjukkan adanya perbedaan yang signifikan antara tingkat komitmen organisasi ASN PNS dengan ASN tenaga kontrak pada pemain wayang orang di Sriwedari $\left(\mathrm{t}_{\text {hitung }}>\mathrm{t}_{\text {tabel, }} p\right.$ value $<0,05$ ) namun tidak terdapat tidak terdapat perbedaan yang signifikan antara tingkat 
Philanthrophy Journal of Psychology

Vol 1 Nomor 2 (2017), 129-142

ISSN 2580-6076 (Print), ISSN 2580-8532 (Online)

komitmen organisasi responden pria dan wanita pada pemain wayang orang di Sriwedari ( $\mathrm{t}_{\text {hitung }}<\mathrm{t}_{\text {tabel, }} p$-value $\left.>0,05\right)$.

\section{Diskusi}

Hasil pada tabel 1 menunjukkan adanya hubungan yang signifikan antara job security dan self perceived employability dengan komitmen organisasi dengan nilai koefisien korelasi ganda (R) menunjukkan angka 0,742 sehingga dapat dikatakan korelasi yang terjadi antara job security dan self perceived employability dengan komitmen organisasi tergolong kuat. Nilai koefisien determinasi $\left(R^{2}\right)$ menunjukkan angka 0,551 atau $55,1 \%$ yang menunjukkan variabel job security dan self perceived employability secara bersama-sama menyumbang sebesar 55,1\% terhadap variabel komitmen organisasi dengan sisanya sebesar 44,9\% dipengaruhi oleh variabel lain yang tidak termasuk dalam penelitian ini.

Hasil analisis korelasi ganda yang dilakukan telah sesuai dengan teori dan penelitian yang menyebutkan job security dan self perceived employability sebagai faktor yang mempengaruhi komitmen organisasi. Job security didefinisikan sebagai keadaan aman dan stabil pegawai dalam melakukan pekerjaannya yang dipengaruhi berbagai karakteristik diantaranya karakteristik pekerjaan, perubahan organisasi, serta perubahan penggunaan teknologi dalam organisasi (Probst, 2002; Herzberg, 1968; Meltz, 1989; Kuhnert dkk., 1989). Selain job security, penelitian ini menunjukkan adanya self perceived employability yang secara bersama-sama dengan job security mempengaruhi komitmen organisasi. Selfperceived employability adalah evaluasi subjektif yang dilakukan individu untuk mengetahui kapasitasnya dalam melakukan pekerjaan agar pekerjaan tersebut dapat sesuai dengan kemampuannya dan terlaksana dengan baik (Rothwell \& Arnold, 2007). Berdasarkan pemaparan yang telah dilakukan dapat terungkap adanya keterikatan antara variabel job security dan self perceived employability secara bersama-sama dengan komitmen organisasi.

Dengan demikian dapat dikatakan pada pemain wayang orang Sriwedari terdapat job security dan self perceived employability. Upaya Dinas Kebudayaan untuk mengangkat pemain wayang orang menjadi ASN telah dapat memunculkan keadaan aman dalam pekerjaan pada pemain serta memunculkan perasaan bahwa pekerjaan yang dilakukan oleh pemain wayang orang memiliki arti berdasarkan evaluasi subjektif pemain. Keadaan aman serta evaluasi subjektif yang dimiliki oleh pemain wayang orang berhubungan dengan 
Philanthrophy Journal of Psychology

Vol 1 Nomor 2 (2017), 129-142

ISSN 2580-6076 (Print), ISSN 2580-8532 (Online)

komitmen organisasi yang dimiliki oleh pemain wayang orang yang dapat ditunjukkan dengan terus ditampilkannya pertunjukan wayang orang oleh pemain.

Uji korelasi parsial data hasil penelitian menunjukkan adanya hubungan yang signifikan antara job security dengan komitmen organisasi dengan signifikansi 0,000 $(p<0,05)$ namun tidak terdapat hubungan yang signifikan antara self perceived employability dengan komitmen organisasi pada pemain wayang orang di Sriwedari Surakarta yang ditunjukkan oleh signifikansi $0,813(\mathrm{p}>0,05)$. Sumbangan efektif job security terhadap komitmen organisasi adalah sebesar 53,6\% sementara sumbangan efektif self perceived employability terhadap komitmen organisasi adalah sebesar 1,4\%. Hasil uji korelasi parsial ini turut menguatkan penelitian yang dilakukan oleh Wong dkk. (2002) dan Yousef (1998) namun tidak sesuai dengan penelitian yang dilakukan oleh De Cuyper dan De Witte (2011).

Tidak signifikannya hubungan self perceived employability dengan komitmen organisasi dalam penelitian ini dapat disebabkan oleh beberapa hal. Self perceived employability sendiri dalam kaitannya dengan komitmen organisasi dipengaruhi oleh faktor work volition yaitu adanya keputusan untuk melakukan pekerjaan dan self efficacy (Ngo, Liu, Cheung, 2017). Kurangnya kesempatan bagi pemain wayang orang untuk menetapkan pekerjaan yang dilakukan sesuai dengan kemampuannya yang disebabkan kondisi lapangan pekerjaan yang terbatas bagi profesi pemain wayang orang. Selain itu dari segi internal individu, self efficacy yang dimiliki oleh pemain wayang orang dapat turut serta mempengaruhi self perceived employability dengan memunculkan selfinterest atau persepsi individu yang mementingkan dirinya sendiri sehingga kurang berkomitmen terhadap organisasi (Bagshaw dalam De Cuyper \& De Witte, 2011). Self efficacy dan self interest yang ada pada individu merupakan bagian dari faktor personal dan faktor yang berhubungan dengan suatu peran tertentu pada seseorang turut memberi pengaruh yang signifikan terhadap komitmen organisasi (Abreu, Cunha, Reboucas, 2013; Hrebiniak \& Alutto, 1972). Faktor personal pemain wayang orang dengan dasar kemampuan di bidang seni dapat memberi pengaruh terhadap komitmen organisasi pemain wayang orang. Seni mewariskan nilai-nilai kebebasan sebagai dasar untuk menciptakan suatu karya. Kaitan antara kesenian dengan kebebasan merupakan suatu hal yang patut dipertimbangkan dalam bidang ilmu pengetahuan dan moral. (Sleinis, 2003). Adanya nilai-nilai kebebasan yang dianut oleh orang-orang dalam dunia seni berpengaruh terhadap komitmen yang dimiliki (Cennamo \& Gardner, 2008; Odom, Boxx, Dunn, 1990). 
Philanthrophy Journal of Psychology

Vol 1 Nomor 2 (2017), 129-142

ISSN 2580-6076 (Print), ISSN 2580-8532 (Online)

Lebih lanjut, Pada penelitian ini variabel job security memiliki sumbangan yang lebih dominan dibandingkan variabel self perceived employability. Sumbangan yang diberikan variabel self perceived employability terhadap komitmen organisasi relatif kecil yaitu 1,4\% sementara sumbangan yang diberikan variabel job security cukup besar yaitu 53,6\% yang berarti komitmen organisasi pemain wayang orang di Sriwedari lebih banyak dipengaruhi oleh keadaan aman dalam pekerjaan yang diberikan oleh Dinas Kebudayaan berupa pengangkatan pemain menjadi ASN dibandingkan dengan kesesuaian kemampuan yang dimiliki pemain wayang orang dengan pekerjaan yang dilakukan. Saat kedua variabel ini disatukan, variabel job security dapat mengangkat variabel self perceived employability sehingga memiliki hubungan dengan komitmen organisasi pemain, namun apabila dipisah secara parsial, variabel self perceived employability tidak dapat menunjukkan hubungan yang signifikan.

Selanjutnya penelitian ini turut menyertakan analisis tambahan kategorisasi skala komitmen organisasi berdasarkan status kepegawaian dan jenis kelamin. Berdasarkan uji t-tes independen, terdapat perbedaan yang signifikan antara tingkat komitmen organisasi ASN PNS dengan ASN tenaga kontrak pada pemain wayang orang di Sriwedari. Hal ini sesuai dengan penelitian yang dilakukan Clark dan Postel-Vinay (2009) yang menyatakan bahwa pekerja merasa lebih aman ketika menjadi pegawai tetap dibandingkan menjadi pegawai kontrak sehingga pegawai tetap lebih memiliki komitmen organisasi dibandingkan pegawai kontrak. Sementara berdasarkan uji t-test independen berdasarkan jenis kelamin, tidak terdapat perbedaan yang signifikan antara komitmen organisasi pria dan wanita.Hal ini sejalan dengan beberapa penelitian sebelumnya yang turut menyatakan bahwa pada konteks tertentu jenis kelamin tidak memiliki hubungan yang signifikan dengan komitmen organisasi (Intan \& Taurisa, 2012).

Berdasarkan jumlah sumbangan yang diberikan variabel job security dan self perceived employability secara bersama-sama terhadap komitmen organisasi, didapat besar sumbangan 55,1\% dengan 44,9\% berasal dari faktor lain. Komitmen organisasi sendiri dipengaruhi oleh beberapa faktor diantaranya job related factor yaitu faktor yang berhubungan dengan pekerjaan meliputi tingkat keluar masuk individu dalam organisasi, absensi, usaha individu untuk bekerja dalam organisasi, serta peran individu dalam pekerjaan. Lebih lanjut, terdapat beberapa faktor lain yang mempengaruhi komitmen organisasi meliputi kesempatan individu untuk berkembang dalam organisasi, karakteristik pribadi, lingkungan kerja, struktur organisasi, serta gaya manajemen (Kusumaputri, 2015). Adanya berbagai faktor selain job security dan self perceived 
Philanthrophy Journal of Psychology

Vol 1 Nomor 2 (2017), 129-142

ISSN 2580-6076 (Print), ISSN 2580-8532 (Online)

employability berpotensi mempengaruhi tingkat komitmen organisasi individu yang berbeda-beda. Pada penelitian ini belum dicantumkan karakteristik individu yang dapat berpengaruh terhadap komitmen organisasi hanya secara umum diketahui bahwa pemain wayang orang merupakan bagian dari komunitas seniman yang menjunjung nilai-nilai kebebasan dalam berkarya. Sedangkan seseorang dapat dikarakteristikkan berdasarkan teori big 5 personality meliputi keterbukaan terhadap pengalaman baru, conscientiousness atau kehati-hatian, ekstraversi, agreeableness atau mudah bersepakat, dan neuroticism. Kecenderungan individu berdasarkan karakteristik teori ini dapat menunjukkan karakter pribadi tertentu yang berkaitan dengan tingkat komitmen organisasi. Oleh karena itu dalam konteks yang berbeda, faktor-faktor komitmen organisasi dapat memiliki pengaruh yang berbeda dengan besar sumbangan yang berbeda-beda terhadap kekuatan komitmen organisasi yang dihasilkan.

\section{Kesimpulan}

Berdasarkan analisis dan hasil penelitian yang telah dilakukan diperoleh beberapa kesimpulan yaitu terdapat hubungan yang signifikan antara job security dan self perceived employability dengan komitmen organisasi pemain wayang orang yang berstatus aparatur sipil negara di Sriwedari, terdapat hubungan yang signifikan antara job security dengan komitmen organisasi pemain wayang orang yang berstatus aparatur sipil negara di Sriwedari, namun tidak terdapat hubungan yang signifikan antara self perceived employability dengan komitmen organisasi pemain wayang orang yang berstatus aparatur sipil negara di Sriwedari. Status kepegawaian memiliki pengaruh terhadap komitmen organisasi pemain wayang orang di Sriwedari sementara jenis kelamin tidak memiliki pengaruh terhadap komitmen organisasi pemain wayang orang di Sriwedari.

\section{Saran}

Berdasarkan hasil penelitian yang telah dilakukan, peneliti mengajukan saran untuk berbagai pihak. Pertama, pemain wayang orang di Sriwedari perlu lebih menyesuaikan dengan peraturan-peraturan yang diberikan oleh Dinas Kebudayaan. Kedua, Dinas Kebudayaan Surakarta diharapkan menyusun kebijakan untuk mempertahankan keadaan aman yang dimiliki pemain wayang orang salah satunya dengan mengeluarkan kebijakan berupa surat perjanjian antara Dinas Kebudayaan dengan pemain wayang orang yang berisi perjanjian latihan dan frekuensi tampil sehingga terdapat kejelasan peran pemain wayang orang. Selain itu, perlu dipertimbangkan pemberian upah pemain wayang orang terutama 
untuk pemain yang berstatus tenaga kontrak agar pekerjaannya sebagai pemain wayang orang lebih terjamin. Lebih lanjut, dari sisi sosial, Dinas Kebudayaan dapat turut serta memberdayakan masyakarat seperti siswa SD, SMP, SMA untuk menyaksikan pertunjukan wayang orang agar pemain yang menampilkan wayang orang lebih merasa aman untuk orientasi pekerjaannya di masa yang akan datang karena memiliki peran di masyarakat. Untuk penelitian selanjutkan diharapkan lebih memperluas variabel-variabel yang digunakan sehingga didapat pengetahuan yang lebih utuh mengenai psikologi pemain wayang orang di Sriwedari atau Dinas Kebudayaan dan Pariwisata Surakarta serta mempertimbangan waktu dan persiapan penelitian.

\section{Daftar Pustaka}

Abreu, M. C., Cunha, M. C., Reboucas, S. M. (2013). Effect of personal characteristic on organizational commitment: evidence from Brazil's oil and gas industry. The International Journal of Human Resource Management, 24(20), 3831-3852.

Ahimsa, P. (2007) Patron dan Klien di Sulawesi Selatan: Sebuah Kajian Fungsional-Struktural. Yogyakarta: Kepel Press.

Azhari, D. M. (2015). Eksistensi wayang orang (Studi deskriptif eksistensi kelompok wayang orang sriwedari Surakarta, di Surakarta). AntroUnairdotNet, 4(2), 175-185.

Badan Pusat Statistik. (2016, September 20). Mengulik data suku di Indonesia. Badan Pusat Statistik. $\quad$ Retrieved November 11, 2017 from https://www.bps.go.id/KegiatanLain/view/id/127.\%20Diakses\%209\%20SepteSep t\%202016

Cennamo, L., Gardner, D. (2008). Generational differences in work values, outcomes and person-organisation values fit. Journal of Managerial Psychology, 23(8), 891-906.

Clark, A. Postel-Vinay, F. (2009). Job security and job protection. Oxford Economic Papers, 61(2), 207-239.

Cohen, A. (1992). Antecedents of organisational commitment across occupational groups: a meta-analysis. Journal of Organizational Behavior, 13, 539-558.

Dawis R. W., (1992), Person-Environment Fit and Job Satisfaction. New York: Lexington

De Cuyper, N., De Witte, H. (2011). The management paradox: Self-rated employability and organizational commitment and performance. Personnel Review, 40(2), 152-172.

Hadi, S. (2014). Konsep apik dalam koreografi wayang beber. Kawistara, 4(1), 1-110.

Hersapandi. (1999). Wayang Wong Sriwedari: Dari Seni Istana Menjadi Seni Komersial. Yogyakarta: Tarawang.

Herzberg, F. (1968). Work and the Nature of Man. London: Granada.

Hrebiniak, L. G., Alutto, J. A. (1972). Personal and role related factors in the development of organizational commitment. Administrative Science Quarterly, 555-573

Intan, R.. Taurisa, C. M. (2012). Analisis pengaruh budaya organisasi dan kepuasan kerja terhadap komitmen organisasional dalam meningkatkan kinerja karyawan (Studi pada PT. Sido Muncul Kaligawe Semarang). Jurnal Bisnis dan Ekonomi, 19(2).

Kementrian Pariwisata. (2015, Juni 16). Kedudukan, tugas dan tungsi Kementrian Pariwisata. Kementrian Pariwisata. Retrieved November 23, 2017 from http://kemenpar.go.id/asp/detil.asp?c=7\&id=2899 
Kuhnert, K. W., Sims, R. D., Lahey, M. A. (1989). The relationship between job security and employee health. Group and organizational management, 14, 339-410.

Kusumaputri, E. S. (2015). Komitmen pada Perubahan Organisasi (Perubahan Organisasi dalam Perspektif Islam dan Psikologi). Yogyakarta: Deepublish.

Luthans, F. (2005). Organizational Behavior. New York: McGraw Hill

Meltz, N. M. (1989). Job security in Canada. Industrial Relations, 44(1), 149-60.

Meyer, J. P. Allen, N. J. (1991). A three-component conceptualization of organizational commitment. Human Resource Management Review. 1(1), 61-89.

Mowday, R. T., Porter, L. W., Steers, R.M., (1982). Employee-organization linkages: the psychology of commitment, absenteeism and turnover. New York: Academic Press.

Ngo, H., Liu, H., Cheing, F. (2017). Perceived employability of Hong Kong employees: it's antecedents, moderator and outcomes. Personnel Review, 46(1), 17-35.

Odom, R. Y., Boxx, W. R., Dunn, M. G. (1990). Organizational cultures, commitment, satisfaction, and cohesion. Public Productivity and Management Review, 157-169.

Prasetya, E. (2017, Agustus 18). Dari 17.504 Pulau di Indonesia, 16.056 telah diverifikasi PBB. Merdeka Online. Retrieved November 11, 2017 from https://www.merdeka.com/peristiwa/dari-17504-pulau-di-indonesia-16056-telahdiverifikasi-pbb.html

Probst, T. M. (2002). Development and validation of the job security index and the job security satisfaction scale: A classical test theory and IRT approach. Journal of Occupational and Prganizational Psychology, 76, 451-467.

Rothwell, A., Arnold, J. (2007). Self-perceived employability: development and validation of a scale. Personnel Review, 36(1), 23-41.

Sleinis, E. E. (2003). Art and Freedom. Illinois: University of Illinois Press Soedarsono. (1990). Tari-Tarian Indonesia. Jakarta: Proyek Pengembangan Media.

Sumaryoto (1990). Ensiklopedia Wayang Purwa I: Proyek Pembinaan Kesenian Direktur Jendral Kebudayaan. Jakarta: Departemen Pendidikan dan Kebudayaan

Tomascik, T., Mah, J.A., Nontji, A., Moosa, M. K. (1996). The Ecology of the Indonesian Seas. Hong Kong: Periplus Editions Ltd

Wong, Y., Ngo, H., Wong, C. (2002). Affective organizational commitment of workers in Chinese joint ventures. Journal of Managerial Psychology, 17(7), 580-598.

Yousef, D. A. (1998). Satisfaction with job security as a predictor of organizational commitment and job performance in a multicultural environment. International Journal of Manpower, 19(3), 184-194. 